\title{
Comparative study between ultrasound-guided fine needle aspiration cytology of axillary lymph nodes and sentinel lymph node histopathology in early-stage breast cancer
}

\author{
LÍVIO PORTELA CARDOSO-COELHO ${ }^{1}$, RAFAEL SOARES BORGES ${ }^{2}$, AIRLANE PEREIRA ALENCAR ${ }^{3}$, \\ LARYSSE MAIRA CARDOSO-CAMPOS-VERDES ${ }^{1}$, JOÃO PAULO DA SILVA-SAMPAIO ${ }^{1}$, \\ UMBELINA SOARES BORGES ${ }^{1}$, LUIZ HENRIQUE GEBRIM ${ }^{4}$ and BENEDITO BORGES DA SILVA ${ }^{1,2}$ \\ ${ }^{1}$ Postgraduate Science and Health Program, Federal University of Piauí; ${ }^{2}$ Breast Disorder Unit, Getulio Vargas Hospital, \\ Teresina, PI 64001-020; ${ }^{3}$ Department of Statistics, Sao Paulo University, Sao Paulo, SP 05508-220; \\ ${ }^{4}$ Department of Mastology, Federal University of Sao Paulo, Sao Paulo, SP 04024-002, Brazil
}

Received August 24, 2016; Accepted January 31, 2017

DOI: $10.3892 / \mathrm{ol} .2017 .5817$

\begin{abstract}
The replacement of sentinel lymph node biopsy (SNB) by ultrasound-guided fine-needle aspiration (US-guided FNA) cytology of axillary lymph nodes is controversial, despite the simplicity and reduced cost of the latter. In the present study, US-guided FNA was performed in 27 patients with early-stage breast cancer for comparison with SNB. Data were analyzed by calculation of sample proportions. Tumor subtypes included invasive ductal carcinoma (85\%), invasive lobular carcinoma (7\%), and tubular and metaplastic carcinoma (4\%). FNA had a sensitivity of $45 \%$, specificity of $100 \%$, positive predictive value of $100 \%$ and a negative predictive value of $73 \%$. Axillary lymph node cytology obtained by US guided-FNA in patients with breast cancer had a specificity similar to that of sentinel lymph node histopathology in the presence of axillary node metastases. However, when lymph node cytology is negative, it does not exclude the existence of metastatic implants, due to its low sensitivity in comparison to sentinel lymph node histopathology.
\end{abstract}

\section{Introduction}

Breast cancer is the most common malignancy occurring in females from Western countries (1). In Brazil, it has been estimated that 57,960 new cases and 14,207 deaths due to the disease will occur in $2016(2,3)$. Breast cancer prognosis is directly associated with tumor staging at the time of diagnosis $(4,5)$.

Correspondence to: Professor Benedito Borges da Silva, Postgraduate Science and Health Program, Federal University of Piauí and Breast Disorder Unit, Getulio Vargas Hospital, 2280 Avenida Frei Serafim, Teresina, PI 64001-020, Brazil

E-mail: beneditoborges@globo.com

Key words: breast cancer, axillary lymph node, sentinel lymph node, fine-needle aspiration biopsy
For almost a century, radical mastectomy plus axillary lymph node dissection, introduced by Halsted in 1882 until the 1970s of the 20th century (6), was the standard surgical treatment for all breast tumor stages, resulting in serious complications in the upper limb ipsilateral to surgery (7-11).

Breast cancer is currently diagnosed at earlier stages of the disease. The majority of patients have clinically negative axillae. Axillary staging methods that do not require an axillary lymph node dissection have been investigated, as axillary nodal status is the most important prognostic factor and most effective indicator of long-term survival (12-15). Sentinel lymph node biopsy (SNB) is the gold standard for histopathological staging of early-stage breast carcinoma, as information concerning axillary lymph node status is able to be achieved with a lower complication rate (13). However, SNB involves a complex laboratory technique, increasing surgical costs. In addition, clinical complications may arise, including anaphylactic reactions, lower sensitivity and strength of the ipsilateraley upper limb and even the rare occurrence of lymphedema $(16,17)$.

Alternative methods to replace sentinel lymph node biopsy have been assessed (15). Therefore, analysis of ultrasonographic characteristics of axillary lymph nodes, particularly ultrasound-guided fine-needle aspiration (US-guided FNA) cytology is required. The main US features of suspicious lymph nodes are nodal size, cortical thickening, round morphology, hypoechogenicity, loss of central fatty hilum and eccentrically bulging cortex (15). However, thickness of the lymph node cortex is most highly associated with the presence of metastasis and may contribute to US-guided FNA (5). Oz et al (5) revealed that a cortical thickness $>4.0 \mathrm{~mm}$ had a sensitivity of $86 \%$ and specificity of $87 \%$, whereas at the cut-off point of $3.0 \mathrm{~mm}$, specificity decreased to $37 \%$. However, results in the literature are heterogenous, as ultrasonographic examination is operator-dependent and machine-dependent and there is a great variation in sensitivity and specificity when only US is used for evaluation of axillary lymph nodes (18-20). By contrast, using US-guided FNA, certain authors have demonstrated a sensitivity and specificity ranging from 42.2-89 and 
$81-100 \%$, respectively (20-28). US-guided FNA has a high accuracy rate $(5,7)$.

Therefore, controversy concerning US-guided FNA cytology of axillary lymph nodes vs. SNB in early-stage breast cancer, in addition to the paucity of comparative studies between the two methods in Brazilian women, informed the current study design.

\section{Patients and methods}

Patients. The present study involved 30 female patients, aged 33-73 years, diagnosed with operable early invasive breast carcinoma, with any histological tumor subtype and with indications for SNB during surgery. These women had been managed at the Breast Disorder Clinic of the Getulio Vargas Hospital, Federal University of Piaui (Piaui, Brazil) from May 2015 to April 2016. Three patients were excluded from the study due to previous axillary surgeries, allergic reaction to dye injection or refusal to participate in the study. The Internal Review Board of the Federal University of Piaui approved the study and all patients signed an informed consent form prior to admission.

Methods. US-guided FNA of axillary lymph nodes was performed at the most common site for sentinel lymph node (SLN) appearance, representative of benign or suspicious ultrasonographic nodal size and morphological features. A Logiq E portable ultrasound machine (GE Medical Systems, Jiangsu, China), with a $12 \mathrm{~L}$ linear probe, and 7.5 to $12 \mathrm{MHz}$ imaging frequency was used. Contents of the aspirated material were expelled onto a glass slide for cellular distension. The smeared slides were fixed in $99.3 \%$ alcohol (29). The sentinel lymph node was obtained during the scheduled surgical procedure for each patient, following its location by Blue Patent dye V injection or Tc-99 m phytate lymphoscintigraphy scan. A $\gamma$ probe was used intraoperatively to locate the SLN. The SLN was sent to the laboratory without any fixative agent for histopathological examination during the intraoperative period. The analysis of cytology and sentinel lymph node was performed by the same professional, with SLN considered as the gold standard to evaluate the performance of FNA.

Data obtained were stored in an electronic database created in the Excel 2010 program (Windows 7; Microsoft Corporation, Redmond, WA, USA). Subsequently, statistical analysis was performed using calculation of sample proportions in Excel 2010.

\section{Results}

The patients ranged in age from 33-73 years (mean age, 51 years). The mean size of the primary breast tumor was $1.7 \mathrm{~cm}$ (range, 0.7-3.7 cm). There were $23(85 \%)$ invasive ductal tumors, 2 (7\%) invasive lobular tumors, 1 (4\%) tubular tumor, $1(4 \%)$ metaplastic carcinoma and an average of 2 SLNs were removed per patient (range, 1-6) (Table I; Fig. 1). Of the 27 axillae included in the study, 11 (41\%) were positive for metastatic carcinoma according to the SNB. Of these 11 positive cases, US-guided FNA cytology was positive for malignancy in 5 cases $(19 \%)$. None of the FNA cases that tested positive for malignancy were identified in SNBs that were negative
Table I. Characteristics of patients studied.

\begin{tabular}{lc}
\hline Characteristics & Mean (range) \\
\hline Age, years & $51(33-73)$ \\
Tumor size, cm & $1.7(0.7-3.7)$ \\
Sentinel lymph nodes & $2(1-6)$
\end{tabular}

Table II. Comparison between FNA cytology and histopathology in the evaluation of axillary lymph node metastasis in patients with breast cancer.

\begin{tabular}{lccr}
\hline $\begin{array}{l}\text { Histopathology/ } \\
\text { Cytology }\end{array}$ & $\begin{array}{c}\text { With } \\
\text { metastasis }\end{array}$ & $\begin{array}{c}\text { Without } \\
\text { metastasis }\end{array}$ & Total \\
\hline With metastasis & 5 & - & 5 \\
Without metastasis & 6 & 16 & 22 \\
Total & 11 & 16 & 27 \\
\hline
\end{tabular}

Sensitivity, 45\%; Specificity, 100\%; Positive Predictive Value, 100\%; Negative Predictive Value, $73 \%$. FNA, fine-needle aspiration.

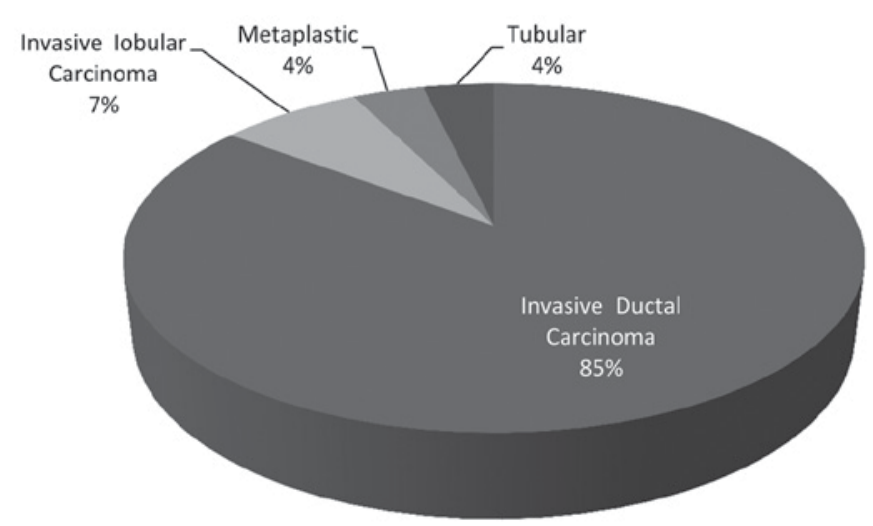

Figure 1. Distribution of subtypes of invasive carcinomas in the sample studied.

for metastatic carcinoma. The sensitivity of SNB cytology was $45 \%$, specificity was $100 \%$, positive predictive value was $100 \%$ and negative predictive value was $73 \%$ in comparison with SNB histopathology (Table II).

\section{Discussion}

Previous studies have revealed certain limitations of fine needle aspiration cytology (FNAC) compared with histopathology of sentinel lymph node biopsy. In addition to US examination, Bonnema et al (30) used US-guided fine needle aspiration in non-palpable axillary lymph nodes of patients with breast cancer and made a comparison with sentinel lymph node histopathology. This previous study obtained a sensitivity of $80 \%$ and specificity of $100 \%$. Subsequently, various other studies were conducted to consolidate this technique, which is simpler and less expensive than SNB in daily practice $(15,16,18,20)$. Nevertheless, all these studies have demonstrated a limiting 
factor in this evaluation, which is a moderate negative predictive value. Negative cytology is not always accurate, as a negative result may not exclude axillary lymph node metastasis since it may be a false negative result, particularly in cases of very small $(<5.0 \mathrm{~mm})$ tumor implants $(7)$. However, at each new study the detection rate increases, due to advances in imaging tests with ultrasonographic devices that reveal more detailed lymph node structure (20).

Therefore, the present study was developed to compare the detection rates of lymph node metastasis by US-guided FNA vs. SNB in women with early-stage breast cancer. The purpose of the study was to corroborate this diagnostic method as an alternative to SNB, which remains the gold standard of care. The number of sentinel lymph nodes detected (a mean of 2 nodes per patient) is consistent with other studies published; however, it has been reported that certain surgeons opt to remove para-sentinel lymph nodes (12).

The moderate negative predictive value is currently the greatest limitation of using FNA. In the present study, the negative predictive value was $73 \%$ due to false-negative cases. This value increases when the method is used in patients regardless of the presence of axillary lymph nodes with altered images suspicious of metastatic implants $(7,18)$. A reason for these false-negative results in FNA may be the failure to detect lymph nodes with small tumor deposits $(<5 \mathrm{~mm})$ or micrometastasis. This false-negative result is similar to that obtained by core-needle biopsy (thick-needle biopsy of tissue sample). In lymph nodes with small metastatic tumor deposits, it is challenging to reach this small area, and the technique is more invasive and expensive $(7,15,31)$. Furthermore, assuring that the removed lymph node corresponds to the sentinel lymph node was not possible.

In the present study, axillary lymph node cytology in patients with early breast cancer in comparison with SNB had 6 false-negative results. Cytology was negative when histological examinations of sentinel lymph nodes revealed metastasis. By contrast, there were no false-positive results, as all positive cytology results were confirmed by sentinel lymph node histopathology. However, FNA sensitivity was low in association with that of SNB. Of the 11 metastatic axillae, only 5 were revealed by FNA, resulting in a sensitivity of only $45 \%$. A probable reason for this discrepancy may be the small sample included in this study, in view of such a prevalent disease. In a study by Oruwari et al (22), the sample was similar, but included patients with more advanced disease. As a result, the sensitivity and specificity were higher. On the other hand, of the 16 patients without axillary lymph node metastasis, all had a negative FNA, and specificity was $100 \%$. Similarly, in 5 patients with positive cytology, all had sentinel lymph node metastasis, and the positive predictive value was $100 \%$.

By contrast, positive fine-needle aspiration may avoid sentinel lymph node mapping in cases where direct axillary lymph node dissection is selected. Whether the performance of axillary lymph node dissection may be avoided in these cases remains unknown. According to the ACOSOG Z0011 (13) and EORTC AMAROS (12) studies, radiotherapy to the axilla minimally affected by metastasis may promote survival rates similar to those of patients undergoing axillary lymph node dissection $(7,32)$. However, an important study reported that positive preoperative cytology indicates a greater extension of axillary metastatic disease. Axillary lymph node dissection may not be avoided in the majority of patients (94\%), which is consistent with inclusion criteria of the ACOSOG Z011 trial. This may avoid sentinel lymph node mapping in these patients, who have a mean number of 4 lymph nodes involved, in addition to extracapsular disease (16).

This method may decrease the cost of sentinel lymph node mapping, which is an invasive method with a longer surgical and anesthetic duration. Furthermore, it requires the use of nuclear medicine for lymphoscintigraphy scan or dyes that may cause anaphylactic reactions. Lymph node dissection may be avoided in cases where the sentinel lymph node is not located, either in obese patients or those with afferent lymphatic vessel congestion by tumor cells $(18,25)$. In addition, the adverse effects of sentinel lymph node mapping, including pain, loss of sensitivity and lymphedema of the upper limb may be prevented $(7,18,19)$. Nevertheless, despite the results of the present study revealing specificity of cytology similar to the SNB, the sample size of this study was small and there is a requirement for further studies with larger sample sizes to improve the analysis of results.

In conclusion, the results of the current study revealed that fine-needle aspiration cytology of breast carcinoma in comparison with histological examination of SNB has a sensitivity, specificity, positive and negative predictive value of 45, 100, 100 and $73 \%$, respectively. Therefore, positive FNA cytology has a specificity similar to SNB in cases of axillary metastatic disease. However, it is not able to rule out metastatic implants when the test is negative, due to its low sensitivity.

\section{References}

1. Shah R, Rosso K and Nathanson SD: Pathogenesis, prevention, diagnosis and treatment of breast cancer. World J Clin Oncol 5: 283-298, 2014.

2. National Cancer Institute (INCA) José Alencar Gomes: Coordination of prevention and surveillance. Estimate for 2016: Cancer incidence in Brazil/INCA-Rio de Janeiro: INCA, 2015. http:// www.inca.gov.br/estimativa/2016/estimativa-2016-2v11.pdf.

3. National Cancer Institute (INCA) José Alencar Gomes: Coordination of prevention and surveillance. Estimate for 2014: Cancer incidence in Brazil/INCA-Rio de Janeiro: INCA, 2014. http:// www.inca.gov.br/estimativa/2014/index.asp?ID=2.

4. National Cancer Institute (INCA) Jose Alencar Gomes: Coordination of prevention and surveillance. Estimate for 2012: Cancer incidence in Brazil/INCA-Rio de Janeiro: INCA, 2012. http:// portal.saude.sp.gov.br/resources/ses/perfil/gestor/homepage/ estimate.

5. Oz A, Demirkazik FB, Akpinar MG, Soygur I, Baykal A, Onder SC and Uner A: Efficiency of ultrasound and ultrasound-guided fine needle aspiration cytology in preoperative assessment of axillary lymph node metastases in breast cancer. J Breast Cancer 15: 211-217, 2012.

6. Plesca M, Bordea C, El Houcheimi B, Ichim E and Blidaru A: Evolution of radical mastectomy for breast cancer. J Med Life 9: 183-186, 2016.

7. Maniero MB: Regional lymph node staging in breast cancer: The increasing role of imaging and ultrasound-guided axillary lymph node fine needle aspiration. Radiol Clin North Am 48: 989-997, 2010.

8. Song SE, Seo BK, Lee SH, Vie A, Lee KY, Cho KR, Woo OH, Cha SH and Kim BH: Classification of metastatic versus non-metastatic axillary nodes in breast cancer patients: Value of cortex-hilum area ratio with ultrasound. J Breast Cancer 15: 65-70, 2012.

9. Abe H, Schmidt RA, Sennett CA, Shimauchi A and Newstead GM: Us-guided core needle biopsy of axillary lymph nodes in patients with breast cancer: Why and how to do it. Radiographics 27 (Suppl 1): S91-S99, 2007. 
10. Krishnamurthy S: Current applications and future prospects of fine-needle aspiration biopsy of locoregional lymph nodes in the management of breast cancer. Cancer 117: 451-462, 2009.

11. Ecanow JS, Abe H, Newstead GM, Ecanow DB and Feske FM: Axillary staging of breast cancer: What the radiologist should know? Radiographics 33: 1589-1612, 2013.

12. Donker M, Van Tienhoven G, Straver ME, Meijnen P, Van de Velde CJ, Mansel RE, Cataliotti L, Westenberg AH, Klinkenbijl JH, Orzalesi L, et al: Radiotherapy or surgery of the axilla after a positive sentinel node in breast cancer (EORTC 10981-22023 AMAROS): A randomised, multicenter, open-label, phase 3 non-inferiority trial. Lancet Oncol 15: 1303-1310, 2014.

13. Giuliano AE, Hunt KK, Ballman KV, Beitsch PD, Whitworth PW, Blumeneranz PW, Leitch AM, Saha S, Mccall LM and Morrow M: Axillary dissection vs no axillary dissection in women with invasive breast cancer and sentinel node metastase: A randomized clinical trial. JAMA 305: 569-575, 2011.

14. Lyman GH, Temin S, Edge SB, Newman LA, Turner RR, Weaver DL, Benson AB III, Bosserman LD, Burstein HJ, Cody H III, et al: Sentinel lymph node biopsy for patients with early-stage breast cancer: American society of clinical oncology clinical practice guideline update. J Clin Oncol 32: 1365-1383, 2014.

15. Fung AD, Collins JA, Campassi C, Ioffe OB and Staats PN: Performance characteristics of ultrasound-guided fine-needle aspiration of axillary lymph nodes for metastatic breast cancer employing rapid on-site evaluation of adequacy: analysis of 136 cases and review of the literature. Cancer Cytopathol 122: 282-291, 2014

16. Boland MR, Prichard RS, Daskalova I, Lowery AJ, Evoy D, Geraghty J, Rothwell J, Quinn CM, O'Doherty A and McDermott EW: Axillary nodal burden in primary breast cancer patients with positive pre-operative ultrasound guided fine needle aspiration cytology: Management in the era of ACOSOG Z011. Eur J Surg Oncol 41: 559-565, 2015.

17. Moorman AM, Bourez RL, de Leeuw DM and Kouwenhoven EA: Pre-operative ultrasonographic evaluation of axillary lymph nodes in breast cancer patients: For which group still of additional value and in which group cause for special attention? Ultrasound Med Biol 41: 2842-2848, 2015.

18. Boughey JC, Moriarty JP, Degnim AC, Gregg MS, Egginon JS and Long KH: Cost modeling of preoperative axillary ultrasound and fine-needle aspiration to guide surgery for invasive breast cancer. Ann Surg Oncol 17: 953-958, 2010.

19. Cho N, Moon WK, Han W, Park IA, Cho J and Noh DY: Preoperative sonographic classification of axillary lymph nodes in patients with breast cancer: Node-to-node correlation with surgical histology and sentinel node biopsy results. AJR Am J Roentgenol 193: 1731-1737, 2009.

20. Pessoa EC, Rodrigues JR, Pessoa CP, Véspoli HM and Uemura G. Axillary lymph node aspiration biopsy guided by ultrasound is effective as lymph node involvement prediction method in patients with breast cancer? Rev Bras Ginecol Obstet 36: 118-123, 2014 (In Portuguese).

21. Deurloo EE, Tanis PJ, Guilhuijs KG, Muller SH, Kröger R, Peterse JL, Rutgers EJ, Valdés Olmos R and Schultze Kool LJ: Reduction in the number of sentinel lymph node procedures by preoperative ultrasonography of the axilla in breast cancer. Eur J Cancer 39: 1068-1073, 2003.
22. Oruwari JU, Chung MA, Koelliker S, Steinhoff MM and Cady B: Axillary staging using ultrasound-guided fine needle aspiration biopsy in locally advanced breast cancer. Am J Surg 184: 307-309, 2002

23. Lemos S, Dias M, Gonçalo M, Pinto E, Fernandes G and Oliveira C: Detection of axillary metastases in breast cancer patients using ultrasound and colour doppler combined with fine needle aspiration cytology. Eur J Gynaecol Oncol 26: 165-166, 2005.

24. Ciatto S, Brancato B, Risso G, Ambrogetti D, Bulgaresi P, Maddau C, Turco P and Houssami N: Accuracy of fine needle aspiration cytology (FNAC) of axillary lymph nodes as a triage test in breast cancer staging. Breast Cancer Res Treat 103: 85-91, 2007.

25. Sapino A, Cassoni P, Zanon E, Fraire F, Croce S, Coluccia C, Donadio $\mathrm{M}$ and Bussolati G. Ultrasonographically-guided fine-needle aspiration of axillary lymph nodes: Role in breast câncer management. Br J Cancer 88: 702-706, 2003.

26. van Rijk MC, Deurloo EE, Nieweg OE, Gilhuijs KG, Peterse JL, Rutgers EJ, Kröger R and Kroon BB: Ultrasonography and fine-needle aspiration cytology can spare breast cancer patients unnecessary sentinel lymph node biopsy. Ann Surg Oncol 13: 31-35, 2006.

27. Popli MB, Sahoo M, Mehrotra N, Chouhury M, Kumar A, Pathania OP and Thomas S. Preoperative ultrasound-guided fine-needle aspiration cytology for axillary staging in breast carcinoma. Australas Radiol 50: 122-126, 2006.

28. Altomare V, Guerriero G, Carino R, Battista C, Primavera A, Altomare A, Vaccaro D, Esposito A, Ferri AM and Rabitti C: Axillary lymph node echo-guided fine-needle aspiration cytology enables breast cancer patients to avoid a sentinel lymph node biopsy. Preliminary experience and a review of the literature. Surg Today 37: 735-739, 2007.

29. Caputo LFG, Mota EM and Gitirana LB: Concepts and methods for the training of professionals in health laboratories. EPSJV 2: 189-213, 2010.

30. Bonnema J, Van Geel AN, Van Ooijen B, Mali SP, Tjiam SL, Henzen-Logmans SC, Schmitz PI and Wiggers T: Ultrasound guided aspiration biopsy for detection of axillary node metastases in breast cancer patients: New diagnostic method. World J Surg 21: 270-274, 1997.

31. Rao R, Lilley L, Andrews V, Radford L and Ulissey M: Axillary staging by percutaneous biopsy: Sensitivity of fine-needle aspiration versus core needle biopsy. Ann Surg Oncol 16: 1170-1175, 2009.

32. Galimberti V, Ribeiro-Fontana SK, Maisonneuve P, Steccanella F, Vento AR, Intra M, Naninato P, Caldarella P, Iorfida M, Colleoni M, et al: Sentinel node biopsy after neoadjuvant treatment in breast cancer: Five-year follow-up of patients with clinically node-negative or node-positive disease before treatment. Eur J Surg Oncol 42: 361-368. 2016. 